International Journal of English Literature and Social Sciences
Vol-6, Issue-1; Jan-Feb, 2021

\title{
Understanding the Caste-Based hierarchical oppression, Social reforms and activism in Bhimayana
}

\author{
Sneha Chakraborty
}

Department of Comparative Literature, Jadavpur University, India

Received: 09 Nov 2020; Received in revised form: 29 Dec 2020; Accepted: 03 Feb 2021; Available online: 28 Feb 2021

(C2021 The Author(s). Published by Infogain Publication. This is an open access article under the CC BY license

(https://creativecommons.org/licenses/by/4.0/).

\begin{abstract}
The caste-based hierarchical oppression was embedded as a major hegemonic and internalized truth in the Indian subcontinent. Even in the 21st century, caste-based social oppression is a crude reality of India which operates on different levels. Apart from fighting against the colonial power, India was divided internally which caused social injustices and atrocities to communities based on their caste and class. The paper would locate "Bhimayana" as the pioneering text, accounting for the life of Dr. B.R Ambedkar and understand its hierarchical politics on the ritualistic belief of 'impurity' associated with the notion of birth. It aspires to delve deeper into caste-based politics, social activism, and reforms in the Indian Varna system. The graphic novel by Sri Vidya Natarajan and S.Anand talks about the life journey of Dr. Ambedkar, as the revolutionary agent to combat the regressive system of social immobility as an organic and unchangeable biological entity to the 'marginalized community'. It would highlight its resemblance with "Ramayana", the journey of Rama, and the iconic figure in the Indian epic tradition. The beauty of "Bhimayana" lies underneath its unique form of metaphors and the message that it wants to portray. The paper would critically analyze the atrocities attributed to them and how the novel became the raging voice to fight against the system with its folkloric anecdotes and subtle interpretations. It would try to understand how the structure of the novel holds an impetus to fight against this crude system by amalgamating people across different communities to construct "Bhimayana" as a central novel against caste-based oppression and becoming a catalyst of hope and positivity to the world.
\end{abstract}

Keywords-caste, oppression, narrative discourse, social activism, Varna system

\section{INTRODUCTION}

"Bhimayana" depicts the journey of Dr. B.R Ambedkar from a member of the Mahar community to being one of the most prominent leaders to fight against the social oppression for the 'marginalized' community. He brought a positive change by fighting for a separate electorate for the community, to provide them with social empowerment, and gather their collective participation in Indian politics. The biographers, S. Anand and Shri Vidya Natarajan created an equal space of collaboration with the illustrators to create its narrative structure. The novel included a particular section where the illustrators have interpreted the influence of Dr. Ambedkar in their lives, particularly in the Dalit perspective through its narrative structure. The novel tried to portray the life led by Dr. Ambedkar as a member of the Mahar community which was filled with disillusionment, betrayal, and marginality because of its position in the social ladder with the constant atrocities of the crude caste system. The paper will give an inhibited insight into the thrust of social exclusion experienced by him throughout his life. Though it contains the life experiences of Dr. Ambedkar, his social struggles get accumulated to project the collective despair experienced by the marginalized communities. It will also explore how "Bhimayana" becomes important to project the sociopolitical and hierarchal oppression by focusing on the "upper-caste psychology" which believed in trampling people by assigning the notion of "ritualistic impurity" on them. It will trace the ideologies predicated upon through symbols and analogies to analyze the unique form of

ISSN: 2456-7620 
storytelling. It opened an equal space of knowledge between two communities and resulted in creating a revolutionary step in the marginalized literature. Therefore, it has the potential to encourage an in-depthanalysis of a narrative dedicated to the life of a political icon by upholding the spirit of equality envisioned by him in the journey towards social justice. This will not only open newer perspectives in the tradition of graphic narrative (for Indian tradition) but also examine the unique way of "icon making" through its storytelling format. This may further help in opening newer paths of research in the field of 'marginalized literature' for young scholars.

\section{LITERATURE STUDY}

Pramod K. Nayar gave an overview of the induced symbols in "Bhimayana" and its role in the post-colonial literary discourse in his paper, "Towards a Post-colonial critical literacy: Bhimayana as the Indian Graphic Novel". He tried to overview the process of cumulating a personal story with the backdrop of the regressive caste system by exploring the genre of biography in the tradition of Indian literature and analyzing its tenets portrayed in "Bhimayana". It also gave an overview of how "Bhimayana" fits into an "interocular field" and becomes a part of the "popular register". This reinforced me to further trace the significance of "Bhimayana" in critical "Marginalized perspective" that succeeded in creating a collaborative space between the cosmopolitan biographers and the traditional illustrators with the production of the distinguished narrative structure to continue with the legacy of the cultural icon.

\section{METHODOLOGY}

This paper would focus to trace "Bhimayana" from the critical Dalit perspective. It will trace down "Bhimayana" as the life journey of Dr. Ambedkar and mainly focus on its caste-based politics. It will gradually look at how "Bhimayana" created a benchmark by establishing its narrative structure with the accommodative voices of people from polarized communities. The visual tropes and the imageries will also be analyzed to mark the milestones achieved by him. This paper would be based on the theoretical study by mainly analyzing the narrative discourse created by S. Anand and Shri Vidya Natarajan in "Bhimayana". It would try to understand Dr. Ambedkar's position in this entire system of caste hierarchy and the attempts made by him to fight against these systemic atrocities as a prominent leader in Indian politics.

\section{THE NOTION OF CASTE AS THE CENTRAL THEME}

The central crux of "Bhimanaya" deals with the crude caste-based politics which was present in the nationalistic discourse of India. Though "caste" is rather a newer connotation, the prevalent structure was the "Brahmanical Varna System". This was the structure of power where the division of labor was based on ritual "purity" and "impurity" in the hierarchal division of "varna'. This included the asymmetrical distribution of social resources and mobility, access to property, emotions, and cultural resonance to both women and 'Shudras'. The division of the social order included - The Brahmins: the highest social position; allowed to read scriptures and uphold authoritarian decisions; The Kshatriyas: the warrior clan; The Vaishyas: included the business professionals and The Shudras: prescribed to serve the other three varnas by doing menial jobs. The Shudras were not given the basic right of sustenance or respect from the society as they were placed at the bottom of the social ladder. They became part of the inviolable varna order and were expected to perform their duties to uphold their "varna-dharma" (varna duty: the tasks assigned to each varna). Dr. Ambedkar had experienced the tremendous thrust of exclusion and socioeconomical discrimination because of his birth in a "Mahar" household, considered to be "untouchables". He went through the rigid practice of untouchability as a child where the social exclusion had both a physical and psychological impact on him. This system predicated upon the marginalized working class was validated by assigning birth-based hereditary professions without any scope for change. "Bhimayana" talks about the extent of the systematic structure of social oppression experienced by the communities A new format had to be introduced for a story talking about a unique narrative discourse about Dr. Ambedkar's journey. It traces his trajectory from being socially distant for his caste identity in his school to his remarkable victory in "Mahad Satyagraha" (1927) depicted in Chapter I (Water). It talks about the act of exclusion that was reaffirmed through the act of inclusion where Dr. Ambedkar faced distinctive social discrimination even after being allowed to study in school. "Caste" was internalized on the minds of people and was reaffirmed at every step of the way. "Bhimayana" projected on the impossibility to eradicate the hierarchal oppression as the emotion of the "structure" would still be embedded in the minds of people. The novel gives several instances like, Dr. Ambedkar being socially excluded in his school due to his caste identity which forced him to sit alone in the courtyard all by himself. This had an enormous impact on his mind as a child and made him distant from any social contracts. They were even 
prohibited to build a well in the proximity of their households; this act of exclusion was proved to be significant for his "Mahad" Satyagraha. The basic right of water was taken away only on the basis of caste identity attributed to the "Mahar" community. This is not only brutal but a shame to the Indian subcontinent which had a rich legacy to behold. The visual trope of Dr. Ambedkar riding on the back of a fish instills a mythological symbolization by the folkloric artists on his success on "Mahad Satyagraha". The historic moment where the "untouchables" were allowed to draw the water from the public tank was beautifully depicted as the symbol of breaking the age-old stereotypes and social manipulation.

However, even today, the social oppression based on caste is prevalent as a hardcore reality in the society where most of the 'intellectuals' practice it daily, either with their housemaids or with menial jobholders. We have become so accepting of this notion that it has become a way of life. The news of lynching, atrocities, domination over them has become an accepted ritual that gets validated in every household. This act of social exclusion and creating a distinction among human beings across communities has become a way of upholding social authority over the "marginalized community" in the "upper caste psychology". It is linked with the constant accumulation and possession of power.

\section{CREATING A NEW SPACE OF COLLABORATION}

Biographers S. Anand and Shri Vidya Natarajan collaborated with the traditional painters from Madhya Pradesh to work on this narrative. The traditional painters, Subhas Vyam and Durgbai Vyam made the illustrations that were inspired from the traditional court painting, "Gond". The world of Dr. Ambedkar opted to embark upon the journey of humanity above caste, class, hierarchy, gender, or race. This envisioned world of social equality was projected through this narrative. The construction of "Bhimayana" from its inception to its conclusion was possible due to the collaborative efforts of the people belonging to different social positions in the society. The biographer, S. Anand united with the traditional painters to merge their perspectives. The illustrators belonged from the Dalit community and had experienced the long-drawn struggles of social oppression. The collaboration of the traditional painters with the cosmopolitan authors created a space of mutual respect and admiration without succumbing to the beliefs of the upper-caste deliberations. They created an equal space to share knowledge while depicting the life of a man who had envisaged an entire world without any discrimination regarding caste, class, race, or gender. Therefore, to make justice of his lifelong struggle, it was necessary to create a platform of mutual dignity and equal opportunities for people belonging from diversified social strata without submerging their creative spirit and the voice of opinion. This cannot be regarded as the act of mere benevolence but the celebration of knowledge between the two communities by creating an equal space of knowledge and art. The folkloric agency was equally important as the contribution of cosmopolitan narrators in the graphic narrative. The wall painting took a distinctive form when it got re-interpreted by the illustrators in the graphic novel. The illustrators tried to display their journey as members of the "marginalized community". The chapters also included certain visual tropes of birds at the end of the pages, where they symbolized the spirit of freedom and emancipation of the illustrators who traveled from their village to experience a corporate experience and nurture the novel with utmost care and affection. The readers are expected to meet the eyes of innocent birds and embrace their creative potential with equal applause. "Bhimayana", became a remarkable example of creating a creative space of social equality. Durgabai Vyam, Subhas Vyam did not know to read or write. They were inclined to an oral form of knowledge and their daughter, Roshni Vyam tried to contribute by fabricating the chapter reading of the novel. The usage of vibrant colors and hues demarcated the symbol of inclusiveness on planet earth. They are illustrated in the "Gond" style which is a form of court painting by upholding the values of Indian tradition. The lack of a proscenium arch or rectangular panel suggests the deliberate attempt to move away from the conventional European model of a graphic narrative. The cover of the story included no background but the symbolic representation of ferocious and timid animals. The ferocious animal represented the Brahmins who persistently violated the rights of the people belonging to the "other community" by projecting atrocities and discrimination towards them.

\section{RESEMBLANCE WITH RAMAYANA}

It is even interesting to analyze the title "Bhimayana", inspired by "Ramayana", or the journey of the Ayodhya King Rama as part of the Indian epic tradition. "Ramayana", talks about the journey of the iconic figure Rama fighting against the social injustices and emerging victorious. The choice of the title can provoke the emotional sentiments of the Indian readers as it is embedded deeply in the culture of the Indian tradition. This draws a parallel between one of the most celebrated heroes of the Indian epic tradition along with the political maestro who fought to bring a positive change to the 
world. This can also be a radical move towards breaking the social exclusivity, associated with the Indian Epics, Vedas, and the Upanishadic tradition. "Ramayana" held an exclusive position in the epic tradition for many years. Only upper-caste men were allowed to enhance their literary understanding or polish their literary understanding by engaging themselves in the epic tradition of India. "Marginalized Communities" were even forbidden to seek pleasure from classical works of literature as it was restricted only for a particular section of the community. Therefore, "Bhimayana" created a space of equal access, accumulation, and assimilation of knowledge across caste, class, gender, and creed.

\section{CONCLUSION}

Jangarh Singh is addressed in the novel as the "tree that sheltered us", by the illustrators. This is again a radical movement and a powerful narrative trope which included celebrating the talent of the traditional painter, Jangarh Singh who had no connection with the urban world neither with "Bhimayana". It was a way to pay respect to this magnum opus for the unfathomable work he has done to elevate the status of traditional painting amidst the consistent social oppression. Therefore, "Bhimayana" is not only the commemoration of the life story of Dr. Ambedkar but a medium to pay respect to the people who have fought their own battles and exemplified their creative brilliance without receiving enough applause or appreciation. It becomes the collective story of mankind with a multitude of perspectives. There is a spiral movement of time that can be observed in the novel with the intersections of time zones from different periods with the incorporation of several segments. The visual trope of Dr. Ambedkar riding on the back of a fish instills a mythological symbolization by the folkloric artists on his success on "Mahad Satyagraha".

"Bhimayana" can be regarded as a magnum opus in the genre of biography as it captures the true essence of the "marginalized literature" not only through the literary symbols and metaphors but by initiating a process of liberation and collaboration between two communities. Therefore, it creates a world of equality by not succumbing to the European form of graphic narrative but by upholding the tradition of the Indian culture of "Gond" painting. The authority of interpretation was bestowed to Subhas Vyam, DurgabaiVyam without hijacking their agency along with the cosmopolitan narrators. They tried to view themselves in the novel, as the representative of the "lower communities" and wanted the readers to feel their presence through the visual allegories which depict their journey from the state of anguish to embracing their culture.

It not only creates an equal platform but outlives the competitive, capitalistic psychology of individuals in the hope of a "wholistic", interdependent world envisioned by Dr. Ambedkar. "Bhimayana" sets an example for the entire world. It did not only try to depict the crude reality of the infamous caste system in India but focuses on the prerogative measures that could be taken to eradicate the caste-based discrimination from the land of India. It is not merely a biography of a cultural icon but a formation of an eminent piece of literature that tried to make a point in the process of its construction. Literature is regarded as a space of creative freedom but we often find people surrendering to the propagandist ideals for individual benefits without proper representation. The process of constructing "Bhimayana" is itself a step forward in changing the world into a more accepting, harmonious place to live in.

\section{REFERENCES}

[1] Natarajan Shree Vidya, Anand. S, Illustrators- Vyam Subhas, Vyam Durgabai, "Bhimayana: Incidents in the life of Bhimrao Ramji Ambedkar" Navayana Publishing House, New Delhi, 2011

[2] Nayar, Pramod.Paper on "Towards a post-colonial critical literacy: Bhimayana and the Indian Graphic Novel, University of Hyderabad, March 2012.

[3] Ambedkar, B.R. Paper on "Castes in India: Their Mechanisms, Genesis and Development", Columbia University, May 1916. Text first printed in Indian Antiquary Vol. XLVI (May 1917)

[4] Rajagopal Indhu, "The Tyranny of Caste: The NonBrahmin Movement and Political Development in South India", Vikas Publishing Company, New Delhi, 1985) 